Fanum

Sociológico

\section{Forum Sociológico}

Série II

$18 \mid 2008$

Explorando os interstícios urbanos

\title{
A Covilhã vista pelos covilhanenses: representações e práticas sobre uma urbanidade em transformação
}

Domingos Vaz

\section{(2) OpenEdition}

1 Journals

\section{Edição electrónica}

URL: https://journals.openedition.org/sociologico/299

DOI: 10.4000/sociologico.299

ISSN: 2182-7427

\section{Editora}

CICS.NOVA - Centro Interdisciplinar de Ciências Sociais da Universidade Nova de Lisboa

\section{Edição impressa}

Data de publição: 1 junho 2008

Paginação: 89-101

ISSN: 0872-8380

\section{Refêrencia eletrónica}

Domingos Vaz, «A Covilhã vista pelos covilhanenses: representações e práticas sobre uma urbanidade em transformação», Forum Sociológico [Online], 18| 2008, posto online no dia 03 dezembro 2012, consultado o 29 março 2022. URL: http://journals.openedition.org/sociologico/299 ; DOI: https://doi.org/10.4000/sociologico.299

Este documento foi criado de forma automática no dia 29 março 2022.

(C) CICS.NOVA 


\title{
A Covilhã vista pelos covilhanenses: representações e práticas sobre uma urbanidade em transformação
}

\author{
Domingos Vaz
}

\section{Introdução'}

O presente texto estuda aspectos associados às representações da cidade da Covilhã e às perspectivas de acção por parte de um conjunto de actores urbanos, individuais ou colectivos, alguns deles com um historial importante no universo urbano local e que intervêm de forma directa ou indirecta na sua evolução ${ }^{2}$. A partir das entrevistas realizadas analisam-se dimensões relacionadas com o passado fabril da "cidade da lã" e com a memória dos covilhanenses muito marcada pelo mundo mono-industrial dos lanifícios, assim como se estudam dimensões que se ligam com o problema da formação de uma nova urbanidade, em particular pela acção da Universidade da Beira Interior na vida urbana. Estudam-se ainda aspectos relacionados com a rede de actores (representações, expectativas e acções por eles desenvolvidas) e que, de algum modo, promovem ou podem vir a promover o desenvolvimento da cidade objecto de análise.

2 A perspectiva analítica adoptada levou a estudar as representações sobre a Covilhã procurando compreendê-las na sua ligação com a própria configuração sociourbanística da cidade enquanto unidade territorializada de pesquisa. A partir de um exercício crítico foram definidas várias categorias de análise (frequência, profundidade, valorização, localismo, cosmopolitismo, visões personalizadas e/ou colectivas, passadas, presentes e futuras, planeamento urbano e concretização de objectivos), a partir das quais se levou a cabo a análise de conteúdo do discurso narrativo das entrevistas, procurando-se interligar as dimensões individuais e as dimensões colectivas, de forma a explicitar o que, no discurso individual dos diversos agentes, estava impregnado de uma concepção construída no e pelo colectivo. 


\section{Os lanifícios, memória e representação}

3 Os centros urbanos sedimentam, com gradações diferenciadas, pontos de ancoragem da memória: lugares onde se reconhecem experiências de um quotidiano mais ou menos afastado, espaços que remetem para um outro tempo e a que só podemos aceder através do testemunho dos mais antigos, que os vivenciaram no passado. Mais do que espaços, ou seja, a extensão de superfície, eles são territórios, porque apropriados pelo social. Mas são, sobretudo, lugares dotados de carga simbólica que os diferencia e identifica, fazendo evocar acções, personagens e tramas. São lugares de memória, como nota Pierre Nora (1986), ou ainda espaços que contêm um tempo, como assinala Paul Ricoeur (1998).

4 Um lugar de memória é um lugar carregado de recordações, aquele em que a história deixa as suas marcas. História e memória accionam, ambas, narrativas do passado que presentificam uma ausência, reconfigurando uma temporalidade escoada. São representações que dão a ver um "acontecido" que, a rigor, não é mais verificável ou sujeito à repetição.

5 Descrever os covilhanenses é reescrever pedaços da sua história, é falar da sua cidade. Cidade que se constituiu como um "enclave da industrialização" (Cabral, 1988; Vaz, 2004), conhecendo um esplendor industrial, onde toda, ou quase toda, a sua população vivia do trabalho da indústria de lanifícios, em que a experiência urbana em pleno território de montanha se distinguiu na geografia da ruralidade mais ou menos profunda das populações dos territórios interiores. $O$ entrelaçamento da fábrica com a malha urbana atingiu uma tal densidade que a Covilhã foi classificada como "cidadefábrica", em contraste com a industrialização de carácter difuso que deu forma a outras zonas do país. Toda a população vivia para as fábricas, de uma forma intensa, viviam e trabalhavam para a lã. Diz-nos um entrevistado:

“As pessoas falavam da indústria constantemente e isso a nível nacional é um caso único. A Covilhã tinha uma parte específica dos têxteis que era os lanifícios, que havia aqui e em mais dois ou três locais, mas o grande centro era aqui. A Covilhã, tinha, assim, a sua importância a nível nacional dada por essa indústria de lanifícios. Acho que era muito assumido por este lado. Em relação ao presente, eu acho que as pessoas continuam a falar nisso, já mais como uma memória" (Animador Cultural, Entrevista n. ${ }^{4}$ ).

6 A simbiose da cidade com os lanifícios é claramente evidenciada. Os lanifícios são um referente constante dos discursos dos actores entrevistados:

"A população inteira da Covilhã trabalhava nos lanifícios, o marido, a mulher, os filhos, todos trabalhavam nos lanifícios." (Ex-Guarda Livros da Indústria de Lanifícios, Entrevista n. 18). "Sim, é uma tradição muito forte. (...) a indústria funcionava manualmente, a maior parte dos teares eram manuais e para efeitos de acabamento, do tingimento, havia já a necessidade de movimentação. Então as fábricas estavam todas junto às ribeiras para fazer essa movimentação das máquinas. Era essa a força motriz antes de haver energia eléctrica" (Ex-Industrial de Lanifícios, Entrevista n.․ 17). "Eu acho que as pessoas ainda pensam muito em termos de lanifícios. (...) mas, continua a haver belíssimos trabalhadores e operários que não há em mais parte nenhuma" (Reformado da Indústria de Lanifícios, promotor dos Concursos de Piano e de Instrumentos de Arco, Entrevista n.. 5).“Os lanifícios foram a base e continuam a ser uma memória vivida (Reformado, exSindicalista nos Lanifícios anterior ao 25 de Abril de 1974, Entrevista n. 21). 
7 Enquanto representação fortemente ligada ao passado da vida dos covilhanenses, a indústria de lanifícios continua a ser mobilizada na construção do imaginário local. Subsiste como imagem central desse passado industrial e operário, e é assumida como atributo urbano distintivo da Covilhã na produção de tecidos, em quantidade e qualidade. A Manchester de Portugal ${ }^{3}$ conheceu períodos áureos de grande produção industrial, onde o esforço e a existência de uma certa "aptidão natural" do labor covilhanense para essa actividade são referidos com orgulho manifesto:

“(...) o homem andava de um lado para o outro do salão, ouvia o barulho das máquinas e era assim que detectava alguma falha, chegava lá perto da máquina e dizia: "Oh Maria, troca lá esse carreto, tira lá o 14 mete lá o 16 que isso não está bem, não me soa, ele era analfabeto e era assim... a percepção que tinha porque nasceu naquilo... (Reformado, ex-Guarda Livros da Indústria de Lanifícios, Entrevista n.. 18).“Era uma aptidão nata para a indústria. Isto é uma coisa muito importante. A pessoa tinha aqui aptidão, era o pai, o filho, era a hierarquia toda familiar com aptidão para a fábrica" (Arquitecto, responsável pelo urbanismo da Autarquia durante anos, Entrevista $\mathrm{n} .{ }^{\circ} 20$ ).

8 Os industriais locais cedo demonstraram possuir espírito de iniciativa, modernizando os equipamentos e criando e sustentando uma Escola Industrial em 1884, mencionada inúmeras vezes, direccionada para apetrechar profissionalmente uma nova era da indústria têxtil ${ }^{4}$. Como se enfatiza nestes depoimentos:

“A este propósito quero-lhe também dizer que houve uma escola aqui, que é a Escola Industrial Campos Melo, que também já tem mais de 100 anos, é velhinha, velhinha mas sem andar de muletas, saíam de lá muitos técnicos cobiçados até no estrangeiro. Eram técnicos especializados. Eu recordo-me do nome de um deles, era o Técnico Debuxador, agora já deve ter um nome mais pomposo. Um Debuxador tinha uma visão extraordinária e uma força também extraordinária. Chegava perto do tear, olhava de soslaio e dizia logo: “isto não está bem!", pegava numa tesoura e cortava aquilo, o tecelão ficava a tremer. Era de um grande saber" (Reformado dos lanificios, Entrevista n.. 19). "Havia até uma determinada altura uma fonte de fornecimento de mão-de-obra com alguma mentalização e com alguma qualificação que saía da Escola Industrial Campos Melo. A maior parte dos que vieram a ser mestres ou que vieram a ter uma certa importância dentro da empresa, vinham daí. Isso infelizmente acabou (Ex-Industrial de Lanifícios, Entrevista n.ำ 17).

9 A composição social da população é um aspecto elucidativo tanto das dinâmicas como das limitações da matriz urbana local. A chegada de mestres e tecelões de França e Itália em finais do século XVII, como de tecedeiros e tintureiros no fim do século XVIII, não deixa de sugerir a actuação de factores próprios de uma situação de urbanidade porque, associada à afluência da população aldeã atraída pelo trabalho fabril, aquela imigração representa a possibilidade de fazer confluir grupos heterogéneos para um espaço comum que é um traço típico das cidades. Contudo, este processo acabaria por conduzir a uma situação de predomínio de um perfil socioprofissional altamente homogéneo, explicado pela prevalência prolongada e esmagadora do operariado industrial que tinha por único contraponto a minoria de proprietários fabris. Este será o perfil sociohistórico que se manteve praticamente inalterado até à década de 1980, e que significou uma estrutura social dicotómica e um mundo profundamente estratificado entre ricos e pobres. Esta realidade é reflectida nos relatos sobre esses tempos passados sendo evidenciada uma clara dicotomia económica, social e até cultural da sociedade da época entre industriais e operários.

10 Até ao último quartel do século XX a cidade caracteriza-se por um tecido muito denso e povoado numa encosta de montanha, no espaço exíguo entre os vales cavados de duas 
ribeiras onde grande parte das unidades fabris se concentrou. Mas aquela estrutura social dicotómica nem sempre era muito visível em termos do tecido urbano, já que as habitações tendiam a ser misturadas nas mesmas ruas. Diz-nos um ex-industrial de lanifícios:

"O condicionamento industrial veio alterar bastante esse quadro, porque as pessoas que tivessem 10 ou 12 teares mecânicos já tinham o direito de aumentar a sua produção, bastando para isso fazer um requerimento. A pessoa podia lá partir o tear de pau, fazia o que queria porque a nós o que nos interessava era o papel. Três papéis daqueles, 3 alvarás de teares manuais permitiam montar automaticamente um tear de ferro (Entrevista n.o 17). "Então esses patrões mandavam construir as suas casas, melhores, nas mesmas ruas. Eu conheci, por exemplo, ali na antiga rua dos Bombeiros havia 4 industriais que moravam ali, no meio dos operários. Entre os anos 40 e 50, o industrial de lanifícios, numa altura em que havia 130 fábricas na Covilhã, quase todas em média com 12,14, 15 teares, como fazia a sua casita melhor do que a dos outros, ainda que nas mesma ruas, tinham também o pavilhão onde faziam a fábrica, às vezes em madeira e a abanar por todo o lado" (Reformado, exGuarda Livros da Indústria de Lanifícios, Entrevista n.ำ18).

11 Porém, essa estratificação social dicotómica era bem evidenciada na produção de lugares públicos contrastantes e nas modalidades da sua apropriação social. Estes eram frequentados, ou só por industriais, ou só por operários.

"Mas estava tudo bem determinado, os próprios cafés também assim eram. Havia o café Monte Alto, que era onde hoje está o Banco Atlântico, onde só iam os patrões industriais de lanifícios e alguns quadros médios. Isto nos primeiros tempos, porque depois já começou a ser frequentado por outras pessoas. Havia também o Café Central que era onde hoje estão os correios, em frente do Bar Cívico. Este já era mais aberto, já lá iam os quadros médios. Havia ainda o café Montanha que ainda hoje existe mas já não tem esse nome, que é na rua Direita. Este café era dos operários. Havia também o Café Leitão que era em frente do Banco Totta e Açores, onde está a Farmácia Pedroso, ao lado do Banco Borges e Irmão. Esse também era só para os operários, mas daqueles operários com uma visão que procuravam mudar o mundo e já tinham uma ideologia, uma perspectiva de defender a classe... (ibidem)

12 São relatadas algumas tentativas para superar as sucessivas "crises" da produção, apostando-se na modernização de máquinas e equipamentos. A este respeito o chamado "condicionamento industrial" parece ter marcado um ponto de viragem na evolução da indústria têxtil na cidade e região, ao incrementar a dimensão das unidades produtivas através da aquisição de alvarás e instrumentos de trabalho dos teares manuais. Mas também era limitativo e muito pernicioso para o trabalhador individual e familiar que proliferava em instalações domésticas (se exceptuarmos alguns bairros tipicamente operários que se distinguem na malha urbana).

13 A incidência do "condicionamento industrial" teve consequências díspares consoante as situações concretas. Nos casos em que as pessoas já tinham uma certa idade a eliminação dos teares de pau terá permitido a essas famílias fazer algumas economias pela "valorização" desses teares, muitos já em fim de vida. Mas não deverá negligenciar-se os seus efeitos perniciosos na aceleração do fim de uma produção domiciliária artesanal que era o sustento de muitas famílias.

14 Foi, certamente, assim incrementada a dimensão das empresas e, ao mesmo tempo, permitido o aumento do número de firmas. De acordo com as informações obtidas, por volta de meados do século XX na Covilhã chegou a haver centena e meia de firmas, embora na sua maioria de pequena dimensão. As unidades maiores eram as de tecelagem, que beneficiavam da liberdade de comprar um, dois ou três teares ao mesmo 
tempo. Mas, ainda assim, as dimensões na tecelagem eram médias, nunca atingindo dimensões muito grandes. O que veio depois incrementar muito o desenvolvimento, quer em termos de dimensão quer em termos tecnológicos, foi outro factor, que estimulava quem introduzisse a fiação de penteado ${ }^{5}$. Outro aspecto modernizador foi o aparecimento das fibras sintéticas no fim da década de 1960.

"Sim foi nessa altura que começaram a surgir essas fibras sintéticas que eram importadas, era o polyester e a acrílica. $O$ polyester adaptou-se bem à indústria de lanifícios e a acrílica à indústria das malhas, a acrílica nos lanifícios não teve grande significado mas o polyester sim. Este tinha a vantagem de fazer uma fácil ligação com a lã e de produzir o produto com uma maior resistência e menos sujeito a engelhar. A partir daqui dá-se um desenvolvimento galopante" (Ex-Industrial de Lanifícios, Entrevista n.․17).

Alguns dos testemunhos são atravessados por um sentimento de nostalgia em relação ao passado, em particular relevando a existência de uma expresssiva sociabilidade covilhanense. Associações, clubes e organizações diversas cimentaram uma identidade associativista e colectiva com significado ainda hoje na vida local. Semeou-see cresceu um espírito colectivo de todos trabalharem para o mesmo produto, a lã. A este nível faz sentido, pelo menos no plano das hipóteses, referir estas características como indicativas de uma aproximação da Covilhã à ideia de cidade comunitária, ao conceito de comunidade, e não tanto à ideia de cidade urbana. No sentido em que a cidade se circunscreveu num subsector têxtil, à semelhança do seu acantonamento geográfico, amarrada a um carácter demasiado homogéneo para configurar um aglomerado de gentes e actividades capaz de gerar dentro de si a acumulação de dinâmicas diversas que é um dos traços definidoras do mundo urbano ${ }^{6}$.

Hoje valoriza-se o interesse em respeitar esse passado mantendo vivos os seus vestígios e as suas reminiscências. Em relação ao mundo operário acrescente-se as referências aos edifícios das antigas fábricas, alguns em ruínas, outros reabilitados pela Universidade da Beira Interior, à qual é igualmente atribuído o mérito de ter criado o museu dedicado à história dos lanifícios, o único existente na cidade. Naturalmente, a questão de como posicionar este recurso memorial da biografia da cidade face ao futuro interpela-nos e, por isso, interrogámos os nossos interlocutores.

"Os lanifícios estão ligados à história da Covilhã e fazem parte do seu passado histórico... Existe o Museu dos Lanifícios na UBI, existe uma obra escrita sobre o assunto de Ferreira de Castro, existem também alguns historiadores aqui da região ou mesmo da Covilhã, que têm alguma coisa escrita do assunto. Mas eu estou convencido de que a Covilhã vai ter sempre como símbolo a indústria dos lanifícios" (Ex-Guarda Livros da Indústria de Lanifícios, Entrevista n.ำ18). “Temos de encontrar formas de, com os novos meios de comunicação, não perdermos aquilo que é a nossa cultura, a nossa história e, falando como sindicalista, a própria cultura operária. (Dirigente da União dos Sindicatos Têxteis, Entrevista n.ำ22).

17 Num momento em que a densidade histórica dos aglomerados urbanos adquire uma valorização crescente, a Covilhã tem potencialidade para "recriar" toda uma memória comum e um viver colectivo. Mas como? Eis o que nos diz um outro entrevistado:

"O Museu hoje tem que ser um local de vivências muito fortes e variadas. Não podemos pensar o museu como um local apenas expositor de peças, mas como um local que conte uma história ou várias. Onde as pessoas possam usufruir daquilo que estão a ver. Não é só ver, é sentir e viver aquilo que estão a ver. No caso da Covilhã, se me for permitido ter uma afirmação muito forte nesta matéria, apontava para uma experiência muito diversificada e muito debatida ao nível de retratar a história da nossa cidade. Mostrar às pessoas para que elas sentissem tudo isto que é a sua 
identidade. Até com quadros vivos em que as pessoas pudessem contar as suas próprias vivências e sentir que eram parte integrante do próprio local que estavam a ver. Um museu deve ser não só um local onde se tem um grande espólio, mas também e sobretudo um local onde a memória histórica que se conta tenha a ver com o sítio onde ele está implantado" (Presidente Associativo, Entrevista n.o 16).

Parece-nos uma ideia interessante que a cidade poderia dinamizar. A Covilhã pode ambicionar vir a ter o seu "Museu da Cidade" de concepção inovadora, em escala e conteúdos, refuncionalizando um dos seus (muitos) antigos espaços fabris para esse fim. Assim se revalorizaria a articulação indivíduo/sociedade local, dando visibilidade aos recursos identitários que determinaram a cidade como cidade-industrial mas, também, enquanto forma de se reposicionar num contexto alargado marcado pela concorrência inter-cidades.

\section{Com a Universidade o renascimento}

19 A criação do Ensino Superior na Covilhã, com o Instituto Politécnico (1973), foi concebida para servir a indústria de lanifícios. Depois, com o Instituto Universitário (1979) e a Universidade (1986), transforma-se em sinónimo de salvação da cidade e da região ${ }^{7}$. A percepção apurada em relação a esse período industrial é marcadamente negativa e até dramática quanto às consequências do declínio da indústria. A Universidade da Beira Interior emerge num contexto claro de confronto ontológico da cidade consigo própria. Eis alguns traços sintomáticos:

\footnotetext{
"Não há dúvida nenhuma que, se não tem vindo para cá o ensino superior, não teria havido esse efeito de travão que, mesmo assim, não conseguiu travar a avalanche logo na altura" (Ex-Industrial de Lanifícios, Entrevista n.ำ17). "Continuo a dizer que a Covilhã tem estado sempre isolada, tem sempre que ir buscar as forças a si própria. Eu acho que, após o 25 de Abril, em que caiu toda aquela estrutura dos industriais, ficando quase na miséria e quase uma cidade fantasma, dá-se depois a ressurreição das próprias cinzas. o que também contribuiu muito foi precisamente a presença do Instituto Universitário e da Universidade" (Reformado da Indústria de Lanifícios, dinamizador cultural, Entrevista n.ํ5). A Universidade mudou todo o panorama a este nível, ela foi o renascer da cidade. Universidade foi uma mola que fez com que a Covilhã pudesse chegar mais além. Até evitou que ela resvalasse e se tornasse uma cidade mais ou menos fantasma, o que poderia ter acontecido. Acho que as pessoas têm consciência disso" (Reformado, ex-Guarda Livros da Indústria de Lanifícios, Entrevista n. 18). "A cidade saiu de um processo tremendo de recessão económica da década de 70 e inícios de 80 , em que a Covilhã bateu completamente no fundo e a grande almofada foi a Universidade, não em termos de produção mas em termos de consumo. Se não fosse a Universidade o governo central não poderia aqui investir, não poderia investir através de fábricas" (Professor da UBI, Entrevista ก.ำ 1).
}

É consensual a ideia de que a Universidade funcionou como um verdadeiro "ovo de colombo", a termos em consideração as palavras dos entrevistados. Se numa primeira fase o Ensino Superior na Covilhã aconteceu pela "força de meia dúzia" de pessoas, de que não estava ausente uma dose de voluntarismo, depois, e progressivamente, a instituição universitária será génese de dinâmicas locais, sobretudo na esfera do consumo, para "agora ser realmente diferente", ao ponto de se enfatizar os contributos do "mundo universitário" a todos os "níveis", entre eles o do "estudo da própria Covilhã e região". 
21 A este propósito atentemos a esta transcrição emblemática pelo que encerra no domínio da mudança de mentalidades:

“(..) vejo esta cidade perfeitamente transformada. Não é porque se faz mais uma casa, ou se faz mais um bairro, mas a mentalidade desta cidade já não tem nada a ver com o que era há 20 anos. A cidade mudou completamente! Vou-lhe dizer uma coisa, o Ernesto Melo e Castro era um poeta avançadíssimo e foi praticamente corrido da Covilhã! Chamavam-lhe doido! Ele esteve 20 anos sem cá vir e quem o convenceu a vir cá fui eu! Eu escrevi-lhe a dizer que a Universidade mudou completamente a cidade. Ele veio e ele dizia: 'tens razão. Isto é completamente diferente!' Agora ele já tinha com quem falar, tinha interlocutores” (Reformado da Indústria de Lanifícios e Animador Cultural, Entrevista n.ำ5).

22 Ao nível da instrução e do incremento cultural das gentes da Covilhã e da região singulariza-se a situação:

“A Covilhã sempre foi uma cidade que teve a não virtude de não existirem estabelecimentos de ensino. O Liceu veio para cá tardíssimo, não era capital de distrito e não tinha nada a não ser umas escolas particulares, a Escola Central era um incrível edifício a cair de podre. Depois houve um Vitorino Bonina que se debateu de uma forma excepcional para que viesse o Liceu pelo menos até ao 6o ano. Este Vitorino debatia-se muito pelo distrito da Covilhã. Assim, a Covilhã tinha um extremo atraso em termos da cultura de instrução, havia a Escola Campos Melo mas nesse tempo era muito específica para a indústria" (ibidem).

23 São muitas as potencialidades atribuídas à Universidade da Beira Interior, algumas já efectivadas e muitas outras ainda em perspectiva. Deste modo, são fortes as expectativas que os actores depositam nesta instituição, concebendo-a como o grande símbolo da modernidade. Além da repercussão económica, primeira consequência da criação da Universidade ${ }^{8}$, é com optimismo que se anseiam os seus impactes nas dinâmicas de desenvolvimento local e regional.

“Só agora é que a Covilhã está a recomeçar, apesar da Universidade. A Universidade teve uma influência importante, simplesmente os seus efeitos ainda não se fizeram sentir na sua totalidade na região, até porque o desenvolvimento não vem de um dia para o outro. A vinda do ensino superior para a Covilhã coincidiu com uma altura desfavorável, porque se tivesse apanhado uma altura favorável os efeitos eram outros. Por isso é que eu digo que temos de aguardar. As pessoas que se formaram na Covilhã e que ficaram cá ainda são poucas. A maioria vem de fora, mas ainda são poucas. Porquê? Porque ainda não há actividades. Mas a pouco e pouco essas actividades vão aparecendo" (Ex-Industrial de Lanifícios, Entrevista n.․17).

Dando como adquirido os efeitos na atenuação dos impactes sociais originados pelo declínio industrial, existem outros aspectos que relacionam a academia com a mudança, como sejam as dinâmicas culturais geradas e a revalorização de algumas «marcas» da tradição industrial, como seja a requalificação e refuncionalização de edifícios de antigas fábricas. Também a este nível a Universidade intervém como mediação entre uma tradição que assim se preserva e uma modernidade aberta ao mundo e a novos desafios.

"A Universidade estava toda metida dentro de um único sítio da cidade velha, mas quando cresceu para o outro lado a própria cidade velha ficou dentro da Universidade, que está a ser refuncionalizada, não pela Universidade em si, mas pelo o que a Universidade motiva. As dinâmicas que provoca com o parauniversitário, o para-académico, o para-estudantil..." (Professor da UBI, Entrevista n.․ 1).

A este propósito é sublinhada a opção feita pela Academia dando um contributo inestimável na reabilitação de antigos edifícios fabris nos vales das duas ribeiras. A UBI, 
juntamente com a Universidade de Évora, é uma das poucas universidades do país que optou por uma reconversão de edifícios e não pela construção de um campus universitário. A haver um campus na Covilhã ele coincidirá com o próprio casco velho da urbe, atraindo os estudantes, em parte pelas rendas económicas e pela proximidade à Universidade. No centro da zona histórica está localizada a sede da Associação Académica polarizando uma movimentação estudantil significativa o que não deixa de ser indutor de dinâmicas com significado no contexto de uma pequena cidade.

Existe uma consciência clara da necessidade de um estreitamento da relação entre a Universidade e a cidade através da intensificação da cooperação. Porém, apesar de ser comum esta ideia, parece não haver consenso quanto ao modo como essa relação está a ser efectuada. A este respeito é possível identificar duas posições distintas nas percepções dos actores locais inquiridos. Por um lado, defende-se que a cidade está a criar todas as condições necessárias à UBI, sendo esta que, por vezes, nem sempre corresponde. Esta visão é liderada pelo Presidente da Autarquia. Por outro lado, afirmase que a Universidade está a ser subaproveitada pela própria cidade.

“A verdade é que uma cidade com universidade é uma cidade melhor. Uma cidade com universidade é notavelmente uma cidade melhor do que aquelas que não têm universidade. $\mathrm{O}$ que podemos falar não é de que não existe a cidade se não fosse a Universidade, mas sim que a cidade é melhor porque existe a Universidade" (Presidente da Câmara Municipal da Covilhã, Entrevista n.ำ 11). "Penso que a vocação principal da Universidade é formar quadros, formar saberes que, depois, ou a Covilhã tem capacidade para absorver uma boa parte deles ou não tem. Infelizmente nós detectamos que uma parte significativa dos quadros aqui formados não se fixa na cidade nem na região." (Dirigente sindical, Entrevista n.ำ 22). "A Academia não está integrada, ela é uma cidade completamente à parte, muito poucas instituições têm pessoas da Universidade a geri-las e a trabalhar nelas. Eu penso que a cidade olha com grande expectativa para tudo o que é capacidade de conhecimento e do saber que está na Universidade. Eu critico sempre porque é que nós vamos buscar arquitectos a Lisboa, gente de toda a parte do mundo, que não conhecem minimamente a região, e esquecemo-nos que essa reciprocidade poderia e deveria ser mutualista" (Vice-Presidente da Associação Comercial, Entrevista n.. 10 ).

Efectivamente, não seria prudente criar uma universidade no meio de um "deserto", uma universidade inovadora precisa de uma cidade dinâmica e esta será uma interacção sempre fecunda. Este processo tem as suas temporalidades próprias e é, naturalmente, mais moroso do que alguns vaticinam.

As percepções em torno da Universidade ganhariam um novo reforço com a criação da Faculdade de Medicina em 1998. Um acontecimento que parece ter tido a força suficiente para aproximar os próprios actores cujas representações acerca da UBI tendiam a ser menos convergentes. Neste particular relevam-se os contributos da possível e desejada melhoria do sistema de saúde na região, bem como a repercussão ao nível da projecção da imagem no exterior.

"Agora a Universidade é assumida completamente pela cidade e é vista como uma das situações chave para a mesma. Também a Faculdade de Medicina, que em Portugal marca muito a diferença em termos de imagem, faz com que se fale mais da Covilhã e da Universidade. Se calhar agora, uma série de situações que mediatizaram a Covilhã levaram as pessoas a questionarem-se o que será a Covilhã. Agora, para as gerações mais novas, e a Faculdade de Medicina contribuiu para isso também, a visão que prevalece é a de cidade universitária" (Presidente Associativo, Entrevista ก.ํ 3). 
O facto de o Governo ter decidido criar a Faculdade de Medicina mediatizou a Universidade da Beira Interior e o nome da Covilhã. Uma medida recebida com júbilo, de melhoria da auto-estima e reforço da simbiose cidade-universidade. Eis a opinião orgulhosa de um covilhanense:

“Toda a Covilhã gosta da Universidade, admira a Universidade, tem-na até como um emblema. Agora com a Faculdade de Medicina é outro emblema, talvez de maior dimensão até. Aumentou o orgulho, a satisfação, a alegria dos covilhanenses. A Universidade contribui imenso para a vivência das pessoas" (Reformado, exFuncionário de Notariado, Entrevista n.. 19).

Numa pesquisa por nós empreendida a Universidade é representada como um atributo capaz de influenciar o devir covilhanense e que em grande parte determina a autoimagem da própria cidade. Contudo, a afirmação da Academia enquanto factor modernizante parece não se fazer à custa do total declínio dos lanificios, principal predicado tradicional da cidade. O que vem colocar o problema da relação entre modernidade e tradição, do entrecruzamento de elementos quer tradicionalistas quer modernizantes no âmbito de um processo de persistência de uma matriz histórica baseada na relação cidade-

-indústria em paralelo com a assunção da cidade com um novo perfil tendencialmente mais cosmopolita. Independentemente de se caminhar para a "cidade universitária" fica-se com a ideia de a cidade estar indelevelmente associada ao destino da Universidade (Vaz, 2004: 270-278).

\section{O urbanismo como dimensão crítica da nova urbanidade}

$\mathrm{Na}$ representação da cidade intervêm elementos quer tradicionalistas quer modernizantes, uns e outros enquadrando factores de extrema importância na perspectivação do futuro. Um factor não menos significativo é o que reporta à arquitectura e ao urbanismo associado como está à cultura cívica e à qualidade de vida dos cidadãos ${ }^{9}$. Agir sobre o espaço é, em grande medida, agir também sobre a sociedade (Guerra, 2003; Baptista, 2008; Vaz, 2008).

32 Na Covilhã a dimensão urbanística é objecto de inúmeras críticas. Os elementos críticos respeitam tanto à escassez de requalificação dos tecidos antigos como ao débil planeamento das novas frentes de urbanização. Existe uma nítida preocupação em relação ao tema do urbanismo e à forma como os novos espaços residenciais têm sido concebidos e urbanizados atendendo aos seus reflexos na imagem da cidade e na vida dos habitantes. A expansão periurbana sugere uma imagem pouco ordenada e um processo que envolve "grande desperdício imobiliário" com intervenções pontuais e casuísticas que traduzem a ideia de um crescimento em "mancha de óleo" (DGOTDU, 1997). Ao mesmo tempo subtraem-se à cidade tradicional equipamentos e funções de vocação por excelência urbana (biblioteca, cinema, esquadra da polícia...), onde não faltam as estruturas físicas adequadas apesar de carecerem de acções de preservação ou reabilitação urbana, como sejam as muitas ruínas das instalações fabris a precisarem de redefinição funcional. Paradoxalmente numa cidade de pequena dimensão, um efeito essencial deste processo consiste na distinção entre o que é "central" e o que é "periférico", entre a cidade "altaneira" e a cidade "baixa" ou a cidade "antiga" e a cidade "nova", introduzindo-se uma dualização urbana com significado na forma como 
as populações se apropriam do espaço e, naturalmente, com consequência na organicidade do sistema urbano local ${ }^{10}$.

o discurso dos nossos interlocutores é unânime na sensibilização para esta problemática e na crítica às opções urbanísticas dos últimos decénios. As orientações do planeamento urbano, ou a falta delas, são vistas como o "grande insucesso urbano da Covilhã”. Eis algumas afirmações expressivas sobre a questão:

"Repare que nesta cidade ninguém pode passear, é uma cidade onde não vê os pais a passear as suas crianças” (Arquitecto, antigo responsável pelo departamento urbanístico da autarquia local, Entrevista n. 20). "O problema é um problema social e há que resolvê-lo. É preciso reconstruir a cidade aqui, não é fazer coisas de cimento armado de 10 ou 15 andares, isso não interessa. É reconstruir aquilo que está e fazerem casas habitacionais condignas e que as pessoas se sintam lá bem (Reformado, sindicalista anterior ao 25 de Abril de 1974, Entrevista n. 21). "Não é apenas o problema da qualidade estética dos edifícios, mas é também a convivência do edifício com o espaço. Em princípio não devem ser permitidos edifícios que entrem em conflito com a paisagem... a única preocupação que há é meter pessoas em caixotes, não há preocupação de meter pessoas em casas que estejam de acordo com toda a envolvência. (Dirigente Sindical, Entrevista n. ${ }^{\circ} 22$ ).

As mensagens retidas centram-se em torno de dois assuntos fulcrais: a questão da expansão da cidade para a designada zona nova situada num espaço geográfico menos acidentado e a questão da necessidade de requalificar as zonas históricas. Em relação à primeira questão há uma visão crítica e pessimista que tende a ser partilhada pela maioria dos entrevistados. São questionados, sobretudo, o aspecto estético e a volumetria dos novos edifícios. Vejamos:

"Eu acho que na Covilhã os planos de urbanização são um desastre. Mesmo os planos de urbanização lá de baixo foi tudo muito mal pensado, não convida as pessoas. É só construir, construir de qualquer forma, acho que este ponto é o pecado maior da cidade da Covilhã. Isso não faz a qualidade de vida dos seus habitantes. Estão a construir em todo o lado mas sem haver um plano, constroem de qualquer maneira. Já para não falar na questão da zona da Central de Camionagem, aí nem se fala" (Director do semanário local, Entrevista n.ำ14). "A Covilhã não está a crescer, do ponto de vista urbanístico, da melhor forma. As pessoas não gostam de estar encaixotadas. Tirando o Covelo e o Belzêzere, ultimamente os bairros que aparecem não são bairros de vivendas, são bairros em altitude, de grande densidade" (Dirigente Sindical (Entrevista n. .022$)$.

Outros interlocutores expressam uma posição ainda mais crítica ao sustentarem que a Covilhã "na parte que envolve o próprio tecido urbano da responsabilidade da Autarquia, a parte nova, está uma vergonha. Não há uma filosofia, não há um projecto..." (Empresário, Entrevista $n^{\circ}$ 7). Este estado de coisas é atribuído a uma débil cultura de planeamento urbanístico. Os planos de urbanização foram demasiados morosos na elaboração e pouco eficazes na acção, resultando opções de construção e ordenamento territorial algo duvidosas para os entrevistados. Eis o que pensa um interlocutor desta área disciplinar:

"O plano de urbanização estava desactualizado e foram-se encontrando, realmente, soluções não compatíveis com o tecido existente. Eram soluções massificadas que, em grande parte, destruíram o próprio equilíbrio que existia na cidade. Isto ainda prevaleceu durante muitos anos. Depois, começou a era do betão armado, das grandes estruturas e também da ganância das pessoas, dos empreiteiros. Então a Câmara decide mandar fazer um novo plano de urbanização que iria assentar em duas vertentes. A feitura deste plano demorou décadas. Toda a gente à espera do plano e nunca mais dava à luz... O plano deveria obedecer a duas vertentes 
fundamentais: uma era conservar e manter, na parte antiga, as características do tecido urbano existente, embora com intervenções mas que não descaracterizassem o existente; a segunda dizia respeito à zona de expansão, essa já teria vistas mais largas. Ora bem, o plano demorou muito e quando veio foi um desastre porque saiu mal elaborado. Saiu descaracterizador e não contemplava minimamente estas grandes vertentes que devem, realmente, caracterizar um plano de uma cidade de encosta da montanha mais alta e mais bonita de Portugal que é a Serra da Estrela (Arquitecto, antigo responsável pelo departamento urbanístico da autarquia local, Entrevista ก.을).

Quanto à zona histórica da cidade é possível identificar duas posturas distintas, ainda que uma delas seja defendida apenas por um único actor entrevistado. A postura que mais opiniões reúne é a que concebe negativamente a sua actual situação sociourbanística. A propósito é salientado o estado de degradação e despovoamento de alguns "recantos" desse espaço histórico. Assim como são questionados os benefícios que as mais recentes obras no Pelourinho realmente trouxeram à cidade. A outra postura, mais positiva, identificada resume-se à posição do Presidente da Autarquia.

A revitalização da zona histórica central deveria ser uma ambição assumida pela cidade. O núcleo histórico da Covilhã está sujeito a um sério risco. A demolição para construir de novo no mesmo local, a volumetria e densificação resultantes desencadeiam processos de especulação mas não de desenvolvimento. A sua sobrevivência enquanto "conjunto urbano original" requer urgência na criação de uma cultura de conservação, que contrarie a pressão para a demolição, a densificação e a descaracterização. A crescente preocupação com as questões ligadas ao ambiente urbano e à conservação do carácter tradicional dos núcleos antigos resulta da compreensão da importância destes aspectos no desenvolvimento sustentado das cidades e na atracção de novas actividades no terciário superior e no turismo.

"Mas a Covilhã tem um caso singular em relação a outras cidades, é que a Covilhã nunca conservou a sua história. Em nome da indústria que dominou a Covilhã durante mais de um século, fizeram-se as maiores aberrações em toda a cidade, mesmo na parte que é antiga. Por exemplo, a questão da muralha, ela não foi destruída há 20 anos, ela foi destruída há 180 anos, portanto, o património histórico da cidade nunca foi nada preservado. Eu acho que é um assassínio completo alcatroar aquelas ruas. São calçadas e devia-se era proibir os carros de lá passarem e não facilitarem a passagem deles. Toda aquela zona que o Ferreira de Castro fala na "Lã e a Neve", uma pessoa passa por fora e pensa que aquilo não é nada, mas depois passa por dentro e vê que é giríssimo, aquilo é uma ilha dentro da cidade, aquelas ruelas estreitinhas. É uma zona que deveria ser redimensionada e requalificada. Aquele espaço, em termos culturais é uma referência porque o Ferreira de Castro quando fala naquilo fala como sendo uma zona onde viveram os operários" (Agente Cultural, Entrevista n.ำ).

38 As renovações avulsas sem critério e desrespeito pelos valores históricos reúnem opiniões maioritariamente desfavoráveis entre os entrevistados. O programa Polis foi visto como uma esperança para uns e, para outros, como uma oportunidade com um alcance muito limitado. Predomina a ideia de que o programa Polis na cidade ficou aquém das expectativas, sendo, assim, uma oportunidade subaproveitada.

"Porque as pessoas da Covilhã antiga não têm condições modernas actuais de vivência. Por isso estão-se a mudar para os bairros novos, onde têm outras condições. Se o programa Polis, e não só, lhes proporcionar outra forma de viver, eles ficarão aqui. Eu não espero que a Covilhã seja uma cidade morta como é o centro de Lisboa (Agente Cultural, Entrevista n.ํ5). 
As áreas elegíveis no programa Polis resumiram-se praticamente à promoção da ligação física da cidade às duas ribeiras através da recriação de espaços de lazer e cultura nos seus percursos, deixando de fora todo o "casco histórico" habitacional. Eis alguns testemunhos caracterizadores:

"O Polis é uma manta de retalhos. Esta parte aqui do centro nem faz parte do projecto Polis (trata-se da reformulação da Praça do Pelourinho). Esta intervenção é uma adjudicação do Presidente da Câmara. O Polis parece-me que, segundo aquilo que eu tenho lido, tem na sua génese dois objectivos fundamentais: um é preservar a traça do tecido urbano dos centros históricos e das cidades antigas, muito embora admita intervenções que valorizem os espaços, os jardins, as ruas, etc., sem ferir a harmonia e o equilíbrio existente; o outro objectivo que, do meu ponto de vista, é muito importante é a humanização das cidades. A humanização das cidades significa restituir os espaços públicos, as ruas, os jardins, as praças, etc., ao homem. Torna o homem o rei da cidade! Embora possam ter interesse estas soluções mas não deixam de ser soluções pontuais, não sei se inseridas ou não no contexto global do Plano de Urbanização da Covilhã (Arquitecto, antigo responsável pelo departamento urbanístico da autarquia local, Entrevista n.. 20). "O Polis, independentemente das apreciações sobre o investimento e sobre a forma com vai ser gerido, elimina a cidade, está centrado nas ribeiras. Acho que se perde uma grande oportunidade, era muito importante que nestes 6 anos se recuperasse a zona histórica da cidade. Porque o centro da cidade está envelhecido, a população está envelhecida, as pessoas mais novas foram tiradas para a periferia, para o tal crescimento das freguesias em volta." (Dirigente Sindical, Entrevista n.․․ 22).

As intervenções urbanísticas e arquitectónicas da cidade, em particular nas suas áreas consolidadas historicamente, devem ser encaradas como uma procura sempre renovada para "reinventar" o património simbólico urbano, ainda que este seja dominado na Covilhã por especificidades inerentes a conjuntos edificados tipicamente serranos. 0 património classificado pouco reflecte, não só quantitativa como qualitativamente, o passado histórico e fabril da cidade. A valorização do seu património industrial é um fenómeno recente, assumindo uma importância que inicialmente se lhe não adivinhava. o seu reconhecimento deve-se sobretudo ao peso simbólico que continua a carregar, num período que pode caracterizar-se pela revalorização do carácter histórico dos lugares (Vaz, 2004). Face à possibilidade de erosão das suas raízes identitárias, os indivíduos procuram no passado e na memória das cidades compensação para a "correspondente e desconcertante ambivalência de valores", como escreve John Urry (1995: 234). Isto vem colocar às cidades a exigência de uma contínua valorização e aprofundamento do respectivo património histórico.

\section{Capital social}

Pretende-se neste ponto abordar as modalidades de trabalho entre actores, apurar da sua natureza estratégica ou casuística, bem como das suas bases formais e informais de contratualização ${ }^{11}$. O capital social é aqui entendido como um valor que resulta das relações de reciprocidade interinstitucional, determinadas por redes sociais, para a concretização de objectivos mútuos em favor de um conjunto de actores ou de uma comunidade (Shuller et al, 2000; Putnam, 2000). Para além das redes sociais, um outro aspecto determinante para o capital social é a confiança. De acordo com Giddens (1992: 26) a confiança pode ser entendida como "... segurança na credibilidade de uma pessoa ou na fiabilidade de um sistema, no que diz respeito a um dado conjunto de resultados ou de conhecimentos." Sem esta condição de segurança não seria possível os indivíduos 
e as instituições concretizarem relações de reciprocidade, a médio e a longo prazo, evitando que as ligações se tornem efémeras, propiciando o individualismo e não a mutualidade. Efectivamente, a confiança é um requisito imprescindível para se gerar algum capital social, para se gerar a conectividade que estimule a associação de pessoas e instituições em torno de objectivos e de realizações mútuas.

Em termos expressos, os entrevistados valorizaram a cooperação e as parcerias em torno de projectos estratégicos de optimização de recursos e maximização das oportunidades. Enquadram-se aqui as parcerias não só entre actores da Covilhã, mas também entre agentes, empresas e organizações de diferentes cidades, em particular entre as da região.

“A cidade só pode ser e só será, em minha opinião, um ponto de confluência de muitos interesses, ela só será aquilo que esses interesses forem capazes de fazer. Não acho que haja possibilidades de fazer grandes desenhos que não sejam, de facto, pôr todos os actores a trabalhar lado a lado, organizá-los e onde eles conseguirem chegar será onde a cidade conseguiu chegar (Vice-Presidente da Associação Comercial e Industrial dos Concelhos da Covilhã, Belmonte e Penamacor, Entrevista n. 10). "Há a necessidade de outros canais e há necessidade de desenvolver outros projectos congregadores da região, dos quais se possa tirar o devido potencial e em que as pessoas e as cidades não encarem os projectos só como seus mas que os encarem integrados ao serviço do desenvolvimento de uma região." (Presidente Associativo, Entrevista n.. 16).

Porém, na prática, subsistem algumas reticências às formas de trabalho em cooperação. Enquanto para alguns actores continua a ser difícil, senão mesmo impossível, trabalhar em parceria, por falta de confiança ${ }^{12}$, para outros essa situação tem sido visivelmente melhorada. E, neste caso, importaria esclarecer se existem fundamentos estratégicos ou se, pelo contrário, é a força de circunstâncias conjunturais que "obriga" a trabalhar em conjunto. Esta discriminação nem sempre é clara, além de que se uma dada parceria é determinada por razões pontuais, não deverá ser excluída a própria dinâmica do processo e a possibilidade de poder servir de referência para outras acções subsequentes a levar a cabo pelos mesmos ou por outros actores.

\footnotetext{
"Em termos de parcerias, parece que começa a haver um clima nos agentes económicos de apresentarem projectos em comum. Isso está a ser começado mas não sei se a título experimental e pontual ou se com alguma estratégia. Isso é que é preciso descobrir, se está a ser feito estrategicamente ou se está a ser feito pontualmente para resolver problemas (Presidente Associativo, Entrevista n.. 3). "Não faz sentido, nós no futebol, por exemplo, temos associações como o Sporting da Covilhã, como é a ADE como são outras, mas não faz sentido que se permita que não haja uma articulação de esforços entre aquilo que são os esforços do caso da ADE na formação, que é um clube claramente de formação, e que não se aproveite essa canalização para um outro clube que é de facto aquele que é da competição" (Vice-Presidente da Associação Comercial e Industrial dos Concelhos da Covilhã, Belmonte e Penamacor, Entrevista n.ำ 10).
}

E faz sentido questionar: essas relações entre actores baseiam-se em interacções formalizadas (institucionalizadas e contratualizadas) ou funcionam mais de modo informal, suportadas, sobretudo, na confiança e no conhecimento interpessoal? As modalidades de implementação do trabalho em parceria caracterizam-se, maioritariamente, pela sua natureza informal. Pelo menos na sua primeira fase. A centralidade nas pessoas que essa informalidade implica apresenta vantagens e desvantagens. Se, por um lado, permite acelerar os processos burocráticos com a superação de algumas formalidades, por outro, faz com que o futuro das parcerias fique 
muito dependente das pessoas que estão à frente das instituições num dado momento, podendo ou não haver afinidades entre elas.

"É mais informal. Isto é o grande problema que nós temos, porque quando as questões são feitas com base na confiança pessoal, temos dois tipos de problemas: quando há confiança faz-se, quando não há não se faz" (Presidente Associativo, Entrevista n.․ 3). "Mas a verdade é que o covilhanense em relação ao outro tem sempre uma opinião que assenta sempre numa base sentimental, de ódio, paixão, amor. Nós ou amamos ou odiamos, não somos indiferentes" (Dirigente Sindical, Entrevista n.․ 22). "Mais informais e personalizadas, com base nos conhecimentos que se têm há muitos anos. Se mudasse radicalmente a direcção de uma dessas instituições que não conhecesse a outra, seria difícil voltarem a ter relações. Acho que tudo se passa mais na base do encontro no café e da amizade de muitos anos e de todos nos encontrarmos e falarmos regularmente das instituições. Mas tem havido, nos últimos tempos, uma relação mais formal, mais pensada e estrategicamente mais definida entre todos e assim tem havido uma participação mais institucional" (Presidente Associativo, Entrevista n. 3).

Em termos concretos referem-se algumas acções de parceria em curso ou em vias de implementação. E que pela sua natureza endógena configuram dinamismos emergentes ao nível da articulação entre agentes locais e com efeitos espaciais significativos. Algumas com uma lógica territorial alargada à região ${ }^{13}$.

A criação de um parque tecnológico, o Parkurbis, na zona industrial do Tortosendo, fruto de uma parceria entre a Universidade, a Autarquia e diversas outras entidades locais e do sector financeiro, tem como principal prioridade a incubação de pequenas $\mathrm{e}$ médias empresas, visando a criação de postos de trabalho e desenvolver a economia regional, tornando a sua estrutura produtiva mais intensiva em tecnologia e conhecimento, em particular em quatro áreas: alimentar, software e multimédia, energias renováveis e biotecnologia/medicina.

Um exemplo que tem uma abrangência regional digna de referência é o que progressivamente está a envolver as unidades de saúde da região (Hospitais e Centros de Saúde) em articulação com as actividades da Faculdade de Ciências da Saúde polarizadas no Centro Hospitalar da Cova da Beira.

“Eu acho essas parcerias não só desejáveis, mas indispensáveis, porque no caso das Ciências da Saúde, os hospitais das 3 cidades terão que ser integrados gradualmente na Faculdade de Medicina e isso vai obrigar a um trabalho de conjunto. Isto pode ser, teoricamente, um elemento importante para outras áreas também trabalharem em conjunto, como o caso das águas que já está a acontecer (Director do Semanário Local, Entrevista n.ำ14).

As parcerias são valorizadas em várias outras áreas, incluindo a do turismo. Existem condições favoráveis a diferentes tipos de actividades de recreio e lazer durante todo o ano e ao desenvolvimento de projectos de intervenção nos sectores da educação e turismo ambiental. Contudo, quando questionados sobre as causas de carência de parcerias, os entrevistados salientam o divisionismo que tem por detrás questões de natureza pessoal e política. Seja a desconfiança em relação às intenções e aos ganhos particulares de quem assume o protagonismo de dirigir uma instituição, seja a necessidade de lideranças fortes que consigam demonstrar e convencer a colectividade dos intuitos bem intencionados dos dirigentes. $O$ caso da Serra da Estrela é paradigma de uma complexidade organizativa em que intervêm diversas instituições (Região de Turismo, Parque Natural, Municípios...), cada uma com a sua visão específica. É uma situação que ilustra bem a dificuldade em trabalhar em rede e que necessariamente 
reduz a capacidade de organização institucional na dinamização daquele espaço natural ${ }^{14}$.

O sector turístico regional está em crescimento, tanto rural como urbano, traduzido numa tendência para a oferta de alojamento na Covilhã e na Cova da Beira. Existem várias rotas com interesse cultural e turístico. Algumas delas de carácter exótico e típico carregadas de história e associadas a actividades tradicionais interessantes. A Covilhã é a principal cidade de acesso à Serra da Estrela, que integra condições naturais e paisagísticas excepcionais que lhe conferem uma particularidade única. Mas tarda em aproveitar todos os recursos. O trabalho em conjunto é novamente tido como potenciador de vantagens, mas ainda sem os resultados desejados.

"A força do turismo está, precisamente, na região e não numa cidade A, B ou C. Porque os recursos turísticos são da região. Temos que, devagarinho, ir qualificando e disseminando equipamentos de apoio ao turismo em toda a região, percebendo que todos os recursos, sejam eles castelos, judiarias, vales glaciares, passeios na montanha, absorvem muitos municípios e são vendáveis pela força do conjunto desses municípios e não por um só. Há autarcas que não percebem isso e que entendem que se deve é promover o concelho A ou o concelho B. Isso é antiturismo, dessa forma não se cria nenhum produto turístico atractivo (Presidente da Região de Turismo da Serra da Estrela, Entrevista n.ำ 13).

"E qual o papel da Covilhã nesse contexto? Estrategicamente a Covilhã tende a ser turisticamente cada vez mais a cabeça turística da Serra da Estrela. O turismo de natureza e o turismo cultural. Ora nestes dois âmbitos eu vejo que a Covilhã e a Serra da Estrela têm muito a desenvolver e têm um futuro promissor nesta matéria. (...) cada terra tem que vender aquilo que tem, pelo menos em termos da sua identidade (ibidem).

Em termos turísticos a Serra da Estrela continua a ser o grande cartaz atractivo da cidade. Mas começam a emergir outros recursos turísticos intrínsecos à própria cidade da Covilhã (da arqueologia industrial, à judiaria, ao museu e ao que foram 800 anos a trabalhar a "lã"), ainda que a precisarem de trabalho de organização e sistematização para ganharem consistência e visibilidade.

\section{Conclusão}

51 O estudo das representações sobre a cidade da Covilhã dá conta das significativas mudanças sociais, urbanísticas e económicas que a cidade sofreu nestas últimas décadas. A natureza essencial dessas alterações diz respeito à formação de uma nova urbanidade que se vai afirmando sobre um processo de desindustrialização que noutras cidades e regiões não chegaria a ser tão tardio.

52 A Covilhã constitui-se como verdadeiro enclave da industrialização na geografia interior do País tornado atributo de visibilidade social até à temporalidade recente. A partir da década de 1980 o esplendor da "Manchester" portuguesa dá lugar a uma recessão profunda e a uma descrença generalizada na recuperação do tecido industrial da cidade. Será uma crise que envolve toda a estrutura social local abrindo caminho ao colapso da sua principal vitalidade económica e social: a ancestral mono-

-indústria de lanifícios. Existem representações urbanas expressivas desse tempo organizadas em torno de elementos tradicionais registados na memória coleciva e que actuam como pontos fortes da matriz histórica. A criação da Universidade da Beira Interior (em 1986) responderá ao desmoronamento dos lanifícios com a conversão da 
economia local ao sector terciário, e tornam-na um activo decisivo com capacidade de redefinição do próprio modelo urbano covilhanense.

O novo contexto em recomposição continuada requer um olhar renovado sobre a cidade, e de modo mais profundo, torna premente uma verdadeira reinterpretação do que é, e pode ser, uma cidade média, indo além do plano dos critérios estatísticos para sublinhar antes os aspectos relacionais e as formas de organização em rede. $\mathrm{Na}$ perspectiva do desenvolvimento local admite-se que as cidades médias possuem um posicionamento importante a dois níveis: a existência de uma rede densa de circulação informal de informação e uma proximidade identitária eventualmente propícia à cooperação empresarial e institucional. Na prática todos se conhecem, mas esta situação não parece garantir, de forma automática, um ambiente propício a iniciativas mobilizadoras dos agentes urbanos e a estratégias de base colectiva para o conjunto da cidade.

No domínio urbanístico importa referir que as decisões em matéria de planeamento urbano condicionam a vida colectiva na medida em que a vitalidade da cidade depende das conexões recíprocas entre os diversos tempos da biografia da cidade, para que esta contenha o tempo de todos. Se a cidade deve harmonizar a consciência do passado com o desejo futuro, não pode reduzir-se a um aglomerado de edifícios, deve antes constituir-se como um organismo que hierarquiza e satisfaz inúmeras necessidades, desde as comerciais às residenciais, de trabalho e lazer. Conseguir aprender com as vicissitudes dos tempos e utilizar as "lições" para construir o futuro de forma sustentável é um desafio que se coloca a cidades como a Covilhã.

\section{BIBLIOGRAFIA}

BAPTISTA, L. V. (2008), “Cidades e Arredores: continuidade territorial e reconversões identitárias”, in D. Vaz (org.), Cidade e Território: Identidades, Urbanismos e Dinâmicas Transfronteiriças, Editora Celta, Lisboa, pp. 35-46.

CABRAL, M. V. (1988), Portugal na Alvorada do Séc. XX: Forças Sociais, Poder Político e Crescimento Económico 1890 a 1914, Editorial Presença, Lisboa.

CARVALHEIRO, R. (2008), "Que margens tem o urbano? Modos de olhar e interagir entre a cidade e as serras", in D. Vaz (org.), Cidade e Território: Identidades, Urbanismos e Dinâmicas Transfronteiriças, Editora Celta, Lisboa, pp. 47-64.

DIRECÇÃO-GERAL DO ORDENAMENTO DO TERRITÓRIO E DESENVOLVIMENTO URBANO/ QUATERNAIRE PORTUGAL (1997), Sistema Urbano Nacional - Cidades Médias e Dnâmicas Territoriais, Colecção Estudos 3, Lisboa.

GUERRA, I. (2003), “Tensões do urbanismo quotidiano”, in N. Portas, A. Domingues e J. Cabral (orgs.), Políticas Urbanas. Tendências, estratégias e oportunidades, Fundação Calouste Gulbenkian, Lisboa.

GIDDENS, A. (1992), A Constituição da Sociedade, Martins Fontes, São Paulo. 
NORA, P. (1986), Les lieux de mémoire, Paris, Gallimard.

PUTMAN, R. (2000), Bowling Alone: The Colapse and Revival of American Community, New York, Touchstone Book.

RICOUER, P. (1998), “Architecture et Narrativité”, Urbanisme, (303), Paris.

SHULLER, T. et al. (2000), Social Capital: a review and critique in social capital. Critical perspectives, Oxford, Oxford University Press.

URRY, J. (1995), Consuming Places, Londres e Nova Iorque, Routledge.

VAZ, D. (2008), “Que Rumo para as Cidades do Interior?”, in D. Vaz (org.), Cidade e Território:

Identidades, Urbanismos e Dinâmicas Transfronteiriças, Celta, Lisboa, pp. 1-32.

VAZ, D. (2004), Cidades Médias e Desenvolvimento: o caso da cidade da Covilhã, Edição da Universidade da Beira Interior, Covilhã.

VAZ, D. (2003), Tempos Cruzados na Covilhã: representações urbanas e acção colectiva, Tese de Doutoramento, Universidade da Beira Interior, Covilhã.

\section{ANEXOS}

\section{Fontes}

Arquivo Histórico do Banco de Portugal, informação recolhida sobre o Banco da Covilhã.

Entrevistas semi-directivas, realizadas a um conjunto seleccionado de actores individuais e colectivos da Covilhã.

\section{NOTAS}

1. $O$ autor agradece a Renata Freitas o apoio concedido na organização da informação com vista à aplicação do programa informático SPSS).

2. Baseamo-nos na informação colectada em 22 entrevistas semi-directivas a um conjunto previamente seleccionado e diversificado de actores institucionais e da sociedade civil covilhanense (da Autarquia, da Universidade, da Economia, da Cultura, da Segurança Social, do Operariado, dos Sindicatos e dos Media), que mantêm uma significativa actualidade apesar de realizadas em 2001/2002. Esta edição retoma e redirecciona uma versão prévia da análise das entrevistas apresentada em "Tempos Cruzados na Covilhã: representações urbanas e acção colectiva", Universidade da Beira Interior, Covilhã, 2003.

3. Diz-nos o nosso entrevistado: “A Covilhã, que até lhe chamavam a «Manchester» portuguesa, fornecia as tropas e, como a Inglaterra, a Itália e a França estavam todas envolvidas na Guerra, não produziam" (Entrevista n.. 18). E acrescenta um outro: "Eu no Brasil encontrei lá tecidos com a designação da Covilhã, que eram os mais célebres que havia em São Paulo!” (Entrevista n.ำ 5). Um instrumento que expressa esta apreciável realidade industrial foi a fundação no século XIX de uma instituição financeira na Covilhã, o Banco da Covilhã, com actividade até aos anos 30 do século XX.

4. Criada por Decreto do Ministério das Obras Públicas, publicado em 20 de Dezembro de 1864, embora só em 1884 tenha iniciado a sua actividade, a Escola Industrial Campos Melo constituirse-á durante muitos anos como o único centro de formação profissional do País no ramo têxtil. 
5. No início com os teares manuais a grande parte da produção era de "cardados", tecidos mais grossos, enquanto a fiação de penteado típica de tecidos mais sofisticados e tecidos mais ligeiros, antes importados, está associada a um significativo impulso na produção dada a instalação de empresas para fazer o penteado e que começam a trabalhar em regime de 3 turnos.

6. Partilhamos esta ideia com Ricardo Carvalheiro (2008).

7. A fundação da própria Universidade (1986) esteve associada à tradição do trabalho da lã, tendo sido a licenciatura de Eng. Têxtil a primeira a ser criada, com o objectivo expresso de formar recursos humanos qualificados para a indústria de lanifícios. Este mesmo objectivo já tinha estado na base da criação do Instituto Politécnico (1973).

8. O impacte económico é referido como o primeiro e mais visível, amortecendo as consequências da crise dos lanifícios

9. A Arquitectura é reconhecida como uma actividade de interesse público e um recurso para o desenvolvimento, quer por razões culturais (identidade, património, distinção e notoriedade das cidades), quer por factores económicos (valor acrescentado na qualidade da construção civil, do ambiente urbano e do território), quer por razões sociais (espaços públicos de qualidade, equipamentos colectivos, qualidade de vida, imagem urbana, coesão social), e ambientais (eficiência energética, valorização paisagística).

10. Fazemos aqui referência à reflexão de Luís Vicente Baptista sobre a relação entre as cidades e os "arredores" evidenciando o problema da continuidade territorial, o que lhe permite sugerir uma série de pistas para a pesquisa urbana nos contextos urbanos e metropolitanos contemporâneos (Baptista, 2008: 35-46). Nela discute várias questões das quais destacamos as mudanças morfológicas e as reconversões identitárias, assim como os problemas analíticos levantados por umas e por outras, e a diversidade de situações possíveis de encontrar, entre elas as da coexistência de populações no quadro das distinções étnicas e culturais.

11. Segundo os pressupostos da denominada "análise estratégica" de Michel Crozier, visando a mudança através de um contrato assumido entre os actores, as suas necessidades e aspirações. No seu livro O Actor e o Sistema (1977), Crozier propõe uma "análise estratégica da acção social" que passaria pelo aumento e pela consciencialização da capacidade negocial dos sujeitos, cujos compromissos interactivos gerariam uma sociedade mais adequada aos interesses colectivos. (Ver, deste autor, sobretudo O Fenómeno Burocrático (1963), O Mundo dos Empregados de Escritório (1965), A Sociedade Bloqueada (1970) e Actor e Sistema (1977).

12. "Valorizo as parcerias mas na Covilhã é impossível fazer parcerias", declara um empresário (Entrevista n.o 7).

13. Refira-se a aprovação recente de uma candidatura na área do turismo e do património liderada pelo Município de Castelo Branco e que envolve, pela primeira vez na história recente da região, as quatro maiores cidades da Beira Interior (Guarda, Covilhã, Fundão e Castelo Branco), apresentada à Rede de Competitividade e Inovação no âmbito do QREN. Mas existem dúvidas quanto à consistência de um pensamento subjacente alargado em torno do tema das "redes urbanas" que perdure para além deste projecto específico.

14. Aguarda-se a implementação da nova estrutura reorganizativa definida pelo actual Governo em articulação com o PRACE, tendo sido criadas cinco áreas regionais de turismo com circunscrição territorial correspondente às cinco NUT II e seis pólos de desenvolvimento turístico. Foi reconhecido que o antigo modelo se encontrava desfasado das exigências da realidade turística tanto em termos territoriais como da necessidade de inovação na gestão. 


\section{RESUMOS}

A escala da pequena cidade é hoje um traço marcante da sociedade portuguesa. Por isso justificase uma abordagem às especificidades da Covilhã que se foi constituindo ao longo de séculos como um "enclave" da industrialização em pleno território interior montanhoso. A gradual heterogeneização social da cidade vem-se dando desde há cerca de três décadas sob influência de vários factores: a criação da universidade, a terciarização, a qualificação escolar de segmentos crescentes da população, e a integração num sistema urbano de circulação de pessoas e bens.

Através de uma metodologia qualitativa, ao nível do estudo das representações da cidade, distinguem-se dimensões associadas ao passado fabril e outras ligadas ao período mais recente tendencialmente mais cosmopolita. Num outro plano, estudam-se aspectos relacionados com a rede de actores locais que intervêm de forma directa ou indirecta nas dinâmicas urbanas, sendo assim possível ampliar este contributo de interpretação em torno da formação de uma nova urbanidade na Covilhã.

The scale of the town is now a striking feature of the Portuguese society. Therefore, it is appropriate to make an approach to the specific characteristics of Covilhã, which has been constituted for centuries as an "enclave" of industrialization within a mountainous territory. The progressive social heterogeneity of the city has been happening for about three decades and under the influence of several factors as the creation of the university, the spread of the tertiary sector, the school qualification of growing segments of the population, and the integration into a system of urban movement of people and goods.

Through a qualitative methodology in the study of representations of the city, we can distinguish some dimensions which are associated with a manufacturing past and others related to the latest period tended more cosmopolitan. On another level, we study issues related to the network of local agents, which are directly or indirectly involved in the urban dynamics, and thus getting to a further possible interpretation on the design of a new urbanity in Covilhã.

\section{ÍNDICE}

Keywords: social capital, representation of the city, university, new urbanity, wool factory

Palavras-chave: capital social, lanifícios, nova urbanidade, representação da cidade, universidade

\section{AUTOR}

\section{DOMINGOS VAZ}

Professor Auxiliar, Departamento de Sociologia da Universidade da Beira Interior, e investigador do CesNova, Centro de Estudos de Sociologia da Universidade Nova de Lisboa dmvaz@sapo.pt 